\title{
ESPÍRITUS EN PRISIÓN: UNA ETNOGRAFÍA DEL MUSEO NACIONAL DE COLOMBIA
}

\author{
SPIRITS IN PRISON: AN ETHNOGRAPHY OF \\ NATIONAL MUSEUM OF COLOMBIA
}

\author{
Wilhelm Londoño ${ }^{1}$
}

\begin{abstract}
El Museo Nacional de Colombia es una de las instituciones más antiguas del país. Desde su creación, a inicios del siglo XIX, se ha considerado su tarea principal la preservación del patrimonio nacional. En ese sentido, las diferentes instalaciones que ha tenido el museo durante más de cien años han albergado cosas que se consideran representativas de la identidad colombiana. Dentro de esos objetos, tal vez el principal sea el propio edificio del museo; ello debido a su valor histórico en tanto fue el primer panóptico construido en Bogotá en el siglo XIX. Las únicas personas que han cuestionado valorar una cárcel del siglo XIX como representación de la nacionalidad han sido los grupos indígenas, específicamente los indígenas de la Sierra Nevada de Santa Marta. En varias ocasiones, diversos líderes han objetado dos paradigmas del museo: primero, que tuviera que exhibir cosas de los indígenas; segundo, que las cosas estuvieran albergadas en una prisión. Con estas dos ideas deseo hacer una exploración crítica de las maneras en que se representan las ideas nacionales, las cuales están cargadas de los valores excluyentes del siglo XIX.
\end{abstract}

Palabras claves: Colombia, museo, nacionalidad, historia indígena, etnografía.

The National Museum is one of Colombia's oldest institutions. Since its foundation at the beginning of 19th century, its main function has been the preservation of the country's national heritage. For this reason, the the Museum has for more than 100 years collected and curated materials considered iconic of Colombian identity. Perhaps one of the most important elements its collections is the museum building in itself-a construction of great historic significance as the first panoptic built in Bogotá. The only people who have questioned the historical value of this edifice are indigenous ones, specifically those of the Sierra Nevada de Santa Marta communities in the Caribbean region. On various occasions, the leaders of these communities have objected two important elements of the Museum's doctrine: The first is that the Museum has an obligation to exhibit items made by indigenous people; the second, that these items are currently stored in a prison. Starting from these two ideas, I aim to undertake critical exploration of the ways in which national identity is represented in the Museum as well how these representations are charged with 19th century values.

Key words: Colombia, Museum, Nationality, indigenous history, ethnography.

\section{La Visión Indígena del Museo Nacional}

En noviembre de 2010 se realizó, en la Universidad del Magdalena, Santa Marta, Colombia, un taller que tenía la intención de compartir ideas al respecto de la visión indígena, en especial la de los indígenas de la Sierra Nevada de Santa Marta, sobre lo que oficialmente se conocía como patrimonio arqueológico. Para ello, se invitaron dos personas que han trabajado sobre la temática desde diversas posiciones. El primer invitado era Alejandro Haber, el segundo era el indígena cineasta arhuaco Amado Villafaña. Haber es reconocido en América del
Sur por sus trabajos con comunidades andinas, en especial del norte de Argentina (Haber 2009). En esas investigaciones, Haber ha mostrado cómo la episteme andina, basada en el animismo, utiliza diferentes criterios de relación entre los humanos, los animales y las cosas, lo cual cuestiona la propia episteme moderna y sus nociones de los objetos como inanimados y de la naturaleza como fuente de recursos (dos de las formas básicas con las cuales la episteme moderna genera relaciones). Desde la perspectiva andina, tratar los objetos como "cosas" que pueden ser exhibidas, que pueden ser expropiadas y apropiadas por el Estado, se considera inadecuado

\footnotetext{
1 Programa de Antropología, Facultad de Humanidades, Universidad del Magdalena, Carrera 32 Nro. 22-08, teléfono 5-4301292, Santa Marta, Magdalena, Colombia. wlondono@unimagdalena.edu.co
} 
en tanto desconoce la relación recíproca que hay entre los objetos y las personas (Haber 1999). En el mundo andino, los seres humanos se relacionan con las cosas y los animales a través de la teoría de la crianza. Esta teoría requeriría una extensa explicación, pero para los propósitos de este artículo daré solo un ejemplo. La pala de piedra que sirve para cultivar participa activamente en el proceso criador de la cosecha que ayudará al campesino a criar a su familia, en la misma medida en que la Pachamama cría a los seres humanos (Haber y Gastaldi 2006). De tal suerte que una pala no es un objeto aislado, sino forma parte de una red de relaciones en la cual participa interactuando recíprocamente con animales, seres humanos y otros objetos, todos los cuales se cuidan mutuamente (Haber 2009, Kush1975).

La teoría de la crianza es muy útil para evaluar cómo los museos desconectan de la red de relaciones a los objetos y los convierten en cosas que pueden ser exhibidas (Haber 2008). De tal suerte, los objetos pasan a ser evidencias del pasado y no elementos visibles de las relaciones de crianza (van Kessel y Condori 1992).

Amado Villafaña es indígena arhuaco de la Sierra Nevada de Santa Marta; es un reconocido documentalista indígena que ha producido interesantes filmes que muestran ciertas facetas de la historia indígena narrada desde una óptica local. Entre sus principales trabajos se encuentran Kemamumake (Centro de comunicaciones Zhigoneshi-CCZ), Palabras Mayores (Centro de Comunicaciones Zhigoneshi 2009), y el aún no terminado trabajo Sewá (Centro de Comunicaciones Zhigoneshi s.f). Kemamumake narra la dominación que sufrieron las comunidades de la vertiente oriental de la Sierra Nevada de Santa Marta a cargo de las misiones capuchinas que llegaron allí en la primera mitad del siglo XX. Con base en la idea de que los indígenas eran salvajes, cognitivamente inferiores, el Estado delegó a los capuchinos la "educación" de estas comunidades (Safford 1991). Los académicos que se interesaron por las actividades de los capuchinos en diversas partes del país, en especial en el Putumayo, al sur de Colombia, y en el Cesar, en el norte del país, encontraron que las concesiones hechas por el Estado colombiano a las misiones capuchinas lo que produjeron fue la apropiación de territorios, como también la explotación de la mano de obra indígena (Friede 1963, Bonilla 2006). En el caso del documental Palabras Mayores, Villafaña se interesó en mostrar las problemáticas que padecen las comunidades indígenas de la vertiente occidental de la Sierra Nevada de Santa Marta, como consecuencia de la conversión de su territorio, en especial el del litoral, en puertos carboníferos. Dicho documental cuestiona la manera en que las autoridades gubernamentales manifiestan la no existencia de indígenas en el litoral. Recientemente la prensa colombiana publicó una serie de artículos que mostraban cómo ciertas autoridades locales y nacionales habían certificado, mediante dudosos peritajes antropológicos, que no existían comunidades indígenas al interior del conocido Parque Natural Tayrona (Samper 2011). Este tipo de enunciaciones han estado acompañadas de una estrategia por medio de la cual el Parque Natural Tayrona se ha privatizado (Correa y Torres 2011). Según datos del 2011, de las 15.000 hectáreas de Parque Natural sólo quedan 2.000, pues las 13.000 restantes tienen dueños particulares quienes las han obtenido mediante documentos de dudosa procedencia (Canal RCN 2012).

Para los propósitos de este texto, el documental que más interesa es Sewá. En el mencionado taller, el documental que presentó y comentó Villafaña fue ese. El filme está dividido en dos partes. La primera parte trata sobre los problemas que enfrentan los indígenas de las partes altas de la Sierra Nevada de Santa Marta, pues deben soportar que la guerrilla, el ejército, y los paramilitares, violen territorios sagrados que sólo pueden ser visitados por autoridades políticas (gobernadores de cabildo) y religiosas indígenas (Mama). Ya que las partes más altas de la Sierra Nevada, por encima de los 2.000 metros sobre el nivel del mar, son apetecidas por la guerrilla y los paramilitares para moverse por el norte de Colombia, desde la presidencia de Álvaro Uribe Vélez, y con apoyo del gobierno de los Estados Unidos se financiaron varios batallones, entre ellos el denominado de Alta Montaña, lo cual aumentó las cifras de violaciones de derechos humanos (Tate 2007). Uno de esos batallones se ubicó en la Sierra Nevada de Santa Marta. En el documental Villafaña muestra cómo los Mama cuestionan a los soldados por haber hecho su campamento en una zona de Sewá. Desde la perspectiva occidental, la zona de Sewá haría parte de las formaciones geológicas propias del Páramo caracterizado por la presencia de varias lagunas circundadas por abrigos rocosos. En el filme se puede observar cómo los soldados usaron algunas rocas para proteger sus fogatas del viento, que es fuerte en esta parte de la montaña. 
Por las altas variaciones de temperatura las rocas en mención se quebraron, lo que causó indignación entre los indígenas. En esa escena Villafaña explicaba que las rocas eran Sewá y al quebrarlas era como "quebrar una catedral" (Amado Villafaña, comunicación personal, 2010).

La segunda parte del documental muestra a varios Mama en el sótano del Museo Nacional de Colombia. Se ve que los Mama hablan entre ellos e intercambian frases en tonos enérgicos. Mientras transcurre este intercambio de frases, un primer plano muestra a uno de los Mama preguntando “¿por qué estos espíritus están en prisión?”. Como lo explicaba Villafaña, algunos de los objetos que alberga el Museo Nacional son Sewá. Los Mama estaban cuestionando que esas materialidades fueran tratadas como cosas, que fueran exhibidas, que estuvieran desconectadas de la red de relaciones en las que encuentran su sentido (Haber 2009). El significado de los Sewá no ha sido investigado a profundidad, a pesar de que se menciona parcialmente en las etnografías clásicas sobre los nativos de la Sierra Nevada de Santa Marta. En su célebre libro "Los Kogi", Gerardo Reichel-Dolmatoff (Reichel 1985) señalaba que era muy complicado traducir el concepto, pues no había equivalentes en las lenguas modernas. Reichel-Dolmatoff consideraba que la noción que más se le parecía era la de "poder" (Reichel-Dolmatoff 1985 Tomo II:98). Igualmente recalcaba que Sewá era algo que poseían los individuos y que había diferentes formas de Sewá, que eran accesibles de acuerdo a divisiones de género, edad y estatus religioso. Señalaba, finalmente, que ciertos espacios también podían poseer Sewá. Es decir, la posesión de Sewá no necesariamente es exclusiva de los humanos, ya que el Sewá debe entenderse desde la visión local de las relaciones, tal como lo sugiere Haber para la Puna de Atacama (Haber 2009); Reichel-Dolmatoff decía que entre los Kogi se considera que la esposa es el Sewá del esposo y viceversa (Reichel-Dolmatoff 1985 Tomo II:97). Recientemente Danilo Villafaña, indígena arhuaco, ha escrito sobre los Sewá:

Cada linaje posee unos Sewá específicos, que corresponden a sitios sagrados específicos, que determinan un ordenamiento determinado. La coordinación entre los Mama por medio de la consulta (zhátukwa) en los ezwama, es la que permite determinar las funciones de cada Sewá y de quiénes deben y en qué momento se activan cada uno de los sitios por medio del Sewá.

En los ezwama es donde está la unión de los linajes de los Sewá. Es donde se hacen los acuerdos. Es donde físicamente viven los humanos, son tierras comunales, donde todos pueden ir a adivinar, a realizar las consultas. Desde los ezwama se vigilan todos los sitios sagrados de todo el territorio, ahí es donde se concreta el trabajo de todas las autoridades y se plantean las soluciones de manera concertada. En los ezwama están las máscaras. (Villafaña 2005:1).

Como se infiere de la descripción de Danilo Villafaña, los Sewá están relacionados con los linajes, en consecuencia ellos remiten a relaciones de parentesco. Dichas relaciones están conentadas con espacios específicos que orientan las relaciones de los linajes con el espacio y la sociedad. Esas orientaciones son accesibles por medio de la consulta (zhátukwa) que se hace en los ezwama ${ }^{1}$. Por medio de ese procedimiento, es posible entonces determinar el sentido de los Sewá; el linaje adquiere una orientación que guiará decisiones de diversos órdenes (económicas, políticas y religiosas). Según esta interpretación ezwama es el lugar que da orientaciones, y esas orientaciones se consiguen por medio de los Sewá. Así dice Villafaña que los "sitios se activan" por medio de los Sewá en el marco de la consulta que coordina el Mama. En este sentido los Sewá son cosas que activan los mensajes incrustados en los ezwama que son los lugares donde "físicamente viven los humanos"; son espacios de "consulta", de "adivinación", y esas consultas y adivinaciones se dan por intermedio de los Sewá. En la última frase sugiere Villafaña que en esos espacios están las "máscaras", que las máscaras son Sewá.

El primero en apropiarse de una de estas máscaras en nombre de la investigación antropológica fue el famoso etnólogo alemán Theodor Konrad Preuss (Preuss 1919). Dicha máscara, y su iconografía, se considera relevante dentro de las investigaciones que tratan de entender las relaciones interregionales entre diversos pueblos de Costa Rica, Panamá, Venezuela y Colombia desde periodos prehispánicos (Looper 1996). En Santa Marta, cada día más los jóvenes indígenas de la Sierra Nevada de Santa Marta cuestionan estas preguntas antropológicas (Amado Villafaña, comunicación personal, 2010). 
Evidentemente el Museo Nacional está lleno de objetos traídos de la Sierra Nevada de Santa Marta como resultado de las exploraciones arqueológicas adelantadas en la región. Dichas investigaciones iniciaron sistemáticamente desde la década de 1940 cuando los esposos, Alicia Dussán y Gerardo Reichel-Dolmatoff, establecieron un centro de investigación en Santa Marta (Pineda 2004). Esas actividades de exploración implicaron la recolección de muchos Sewá que estaban en varios ezwama. De esta manera las investigaciones arqueológicas implicaron la extracción de estas materialidades violando las reglas de los linajes, como también entorpeciendo las adivinaciones y las consultas. La arqueología, en consecuencia, supuso el arresto y la llevada a prisión de los mediadores entre la sociedad humana y los sentidos inscritos en los espacios sagrados. En la actualidad muchos Mama tienen dificultades para ciertas adivinaciones, pues carecen de ciertos Sewá específicos que se pueden encontrar guardados en algunas instituciones científicas.

En junio de 2010 varios Mama que se encontraban en la sede de la Casa Indígena de Santa Marta, en la cual opera la organización Gonawindúa Tayrona, fueron a la Universidad del Magdalena (ver Figura 1) a preguntar si allí les podían "vender" algunas cuentas hechas de rocas albergadas en la colección de arqueología. Como lo explicaba el reconocido Mama Ramón Gil, ellos se habían quedado sin estas "cosas" y las necesitaban para hacer las consultas necesarias en el marco de varios proyectos (Ramón Gil, comunicación personal, 2010). Concretamente, necesitaban estos objetos para determinar las acciones que los linajes debían seguir en el marco de la recuperación de cuencas hidrográficas cercanas a la ciudad de Santa Marta (Jorge Sánchez, comunicación personal, 2010). Si bien ellos hubieran podido "fabricar" más Sewá, la premura por el ejercicio de adivinación los llevó a

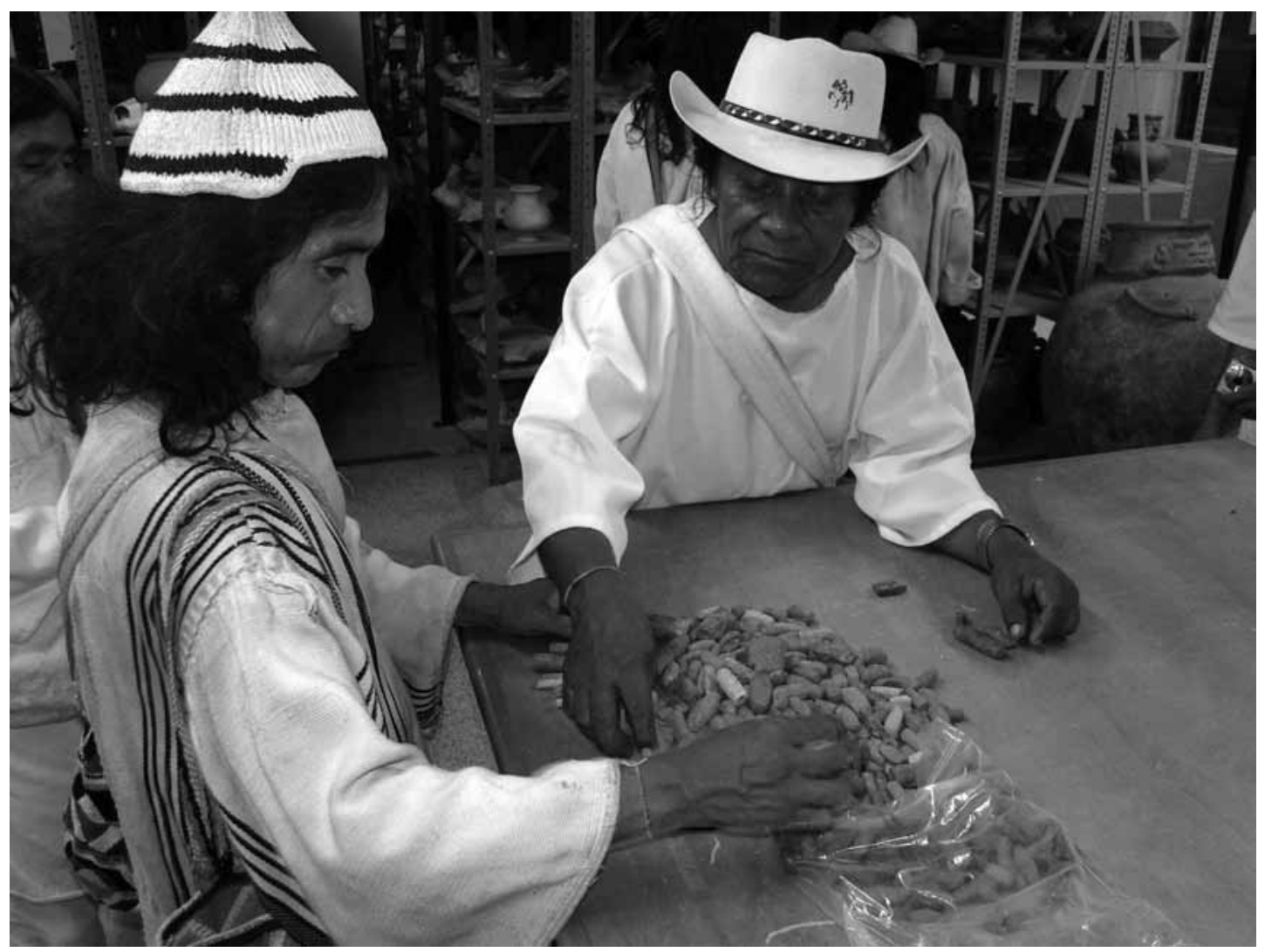

Figura 1. Ramón Gil y otros Mama revisando Sewá en la colección de Arqueología de la Universidad del Magdalena (Foto del autor). Ramón Gil and other Mama reviewing Sewá in the archaeological collections of the University of Magdalena (Photo by the author). 
pensar en la posibilidad de acceder a los que estaban guardados en la colección arqueológica ${ }^{2}$.

Lo que interesa resaltar acá, es que desde la visión de los indígenas de la Sierra Nevada de Santa Marta no existe una noción que ubique estas materialidades como "objetos" que deben ser conservados y exhibidos. Los "objetos" son mediadores y funcionan como vasos comunicantes con los cuales es posible acceder al conocimiento inscrito en el espacio. Tal como ocurría con la episteme del siglo XVI, la naturaleza es una fuente de conocimiento (Foucault 1966) y su interpretación se da por medio de algunos objetos que han venido siendo considerados "arqueológicos". No sobra decir que esta construcción de Sewá en objeto arqueológico es un claro ejemplo de lo que el filósofo colombiano Santiago Castro-Gómez llama, siguiendo a G. Spivak, "violencia epistémica" (Castro-Gómez 2000), es decir, el proceso por el cual la cultura hegemónica impone sentidos diferentes a las culturas subordinadas. La violencia epistémica sería el marco cultural del colonialismo, lo que Walter Mignolo denominaría la colonialidad (Mignolo 2000).

Al usar la visión indígena sobre los objetos, y sobre el propio Museo Nacional (como una cárcel que alberga estos mediadores), se hará una descripción del guion del museo para mostrar cómo ese lugar ejerce una violencia epistémica que ha sido naturalizada a través de las metáforas de la conservación y exhibición del patrimonio nacional. Antes de hacer esa descripción, es necesario hacer una reseña histórica del Museo Nacional que sugiere que la exhibición de objetos indígenas, como la construcción de panópticos, son expresiones de un mismo discurso basado en la metáfora de la civilización (Foucault 1966). Desde ese determinante moderno, los indígenas han sido catalogados como salvajes, de allí que sea válido, en nombre de la museografía, exhibir sus cosas como reliquias históricas (Gnecco y Hernández 2008), ubicarlas en un tiempo diferente al presente (Fabian 1983).

\section{Historia del Museo Nacional}

El Museo Nacional de Colombia es el más viejo del país. Fue fundado en la década de 1820 pocos años después de la independencia nacional (Segura 1995). La fundación del Museo fue producto de las reformas liberales llevadas a cabo por el presidente Francisco de Paula Santanter (Bushnell 1966). Las políticas de Santander tenían como finalidad modernizar la nación, por ello promovió la construcción de colegios y universidades donde se pudieran desarrollar actividades técnicas y científicas. No sobra decir que dichas reformas se basaban en el pensamiento ilustrado fundamentado en la dicotomía salvaje-civilizado (Rojas 2001; Serge 2005). De hecho, muchas de las innovaciones en educación, como en investigaciones sociológicas, tenían como finalidad responder a los cuestionamientos que se hacían desde Europa sobre la imposibilidad de la civilización en América (Langebaek 2003). En ese sentido, la modernización del Estado colombiano suponía la supresión de las formas de alteridad; todos los pueblos que no encajaran en el canon debían ser civilizados por medio de la educación o el exterminio (Londoño 2003, Gnecco y Londoño 2008; Mignolo 2005). Hay que señalar que la política de la disolución de los indígenas venía haciendo carrera desde finales del siglo XVIII; en ese sentido deben entenderse las teorías del intelectual criollo Francisco Moreno y Escandón que en 1779 inició una campaña por la disolución de los resguardos indígenas (Garrido 1993:58), como también las estrategias planteadas por el economista Pedro Fermín de Vargas quien argumentó, a finales del siglo XVIII, que: "sería muy deseable que se extinguiesen los indios, confundiéndolos con los blancos, declarándolos libres del tributo y demás cargas propias suyas, y dándoles tierras en propiedad" (Garrido 1993:99) ${ }^{3}$. Dicha orientación fue heredada por el gobierno republicano. Los primeros actos de gobierno expedidos por Simón Bolívar iban en ese sentido. Por ejemplo, la ley de 11 de octubre de 1821 ordenó la repartición de los resguardos y la consideración de los indígenas como ciudadanos. Esas disposiciones fueron complementadas con otras leyes, como la de 6 de marzo de 1832 que posibilitaba la enajenación de territorios indígenas. Ello estimuló el decreto de 9 de abril de 1832 que disponía la manera de financiar la disolución de los resguardos. La ley de 2 de junio de 1834 fue clara en estipular que una vez disueltos los resguardos, se debían dejar terrenos para alquiler y venta, con lo cual se debían sufragar los agrimensores y los maestros que enseñarían las lógicas de la ciudadanía a los indígenas. Esa tradición jurídica se reflejó en normas como la ley 55 de 1905 que estableció que: "Están vacantes globos de terrenos conocidos como resguardos de indígenas". El artículo 4 de esa norma señalaba que: «Declárense abandonados los resguardos o terrenos correspondientes a poblaciones 
indígenas que han desaparecido». Como era difícil establecer cuándo una comunidad indígena había desaparecido, la reglamentación jurídica, por medio de la ley 104 de 1919, señaló que una comunidad indígena se consideraba como desaparecida cuando tuviera menos de 30 familias o menos de 200 personas (Gnecco y Londoño 2008). Como es de suponerse, diversos terratenientes manipularon estas normativas para extender la frontera agrícola. Durante el inicio del siglo XX muchos archivos muestran los intentos de los terratenientes por demostrar que los indígenas habían desaparecido, como también las apelaciones hechas por los nativos para demostrar lo contrario (Espinosa 2009). No sobra decir que muchos de estos terratenientes fueron los primeros anticuarios cuyas colecciones probaban que los indígenas ya no estaban más. Muchas de esas colecciones hoy hacen parte de las muestras que tiene el Museo del Oro (Sánchez 2003).

De 1823 a 1845 el Museo Nacional estuvo ubicado en el antiguo edificio de la Expedición Botánica. El edificio se llamaba Casa Botánica. Dicha edificación había sido heredada de la antigua expedición científica que desarrolló el imperio español en el Virreinato de la Nueva Granada en lo que se conoce como las reformas borbónicas (Liss 1983); dichas reformas buscaban mejorar las finanzas del imperio por medio de la cuantificación de recursos y la planificación (Walker 1979).

Al final de 1840, hasta 1913, el Museo estuvo ubicado en el edificio del siglo XVII del Colegio de San Bartolomé. Este edificio había sido expropiado por el Estado en medio de las reformas seculares de la segunda mitad del siglo XIX (Lofstrom 1996). Por esa razón, la construcción pasó a llamarse "Salón de las Aulas". Actualmente es el albergue del Museo de Arte Colonial.

En 1913 el Museo Nacional fue trasladado nuevamente a un nuevo edificio. Aparentemente el nombre del edificio era Bulevar Rufino. Dicha edificación estaba relacionada con el crecimiento que tenía la ciudad de Bogotá a inicios del siglo XX. En ese momento la ciudad estaba adquiriendo la fisonomía moderna y ello se reflejaba en la arquitectura (González 2010). De 1922 a 1944 el Museo fue localizado en el antiguo centro comercial Pedro A. López. López fue el primer inversionista en construir edificaciones exclusivas para oficinas en Bogotá (Ríos 2004).

Después de ser trasladado al centro comercial, en 1944, el Museo fue puesto en la antigua penitenciaría de Cundinamarca; dicha edificación era conocida como el "Panóptico". La historia de la penitenciaría es bien conocida (Garzón 2010). En la mitad del siglo XIX el presidente Tomás Cipriano de Mosquera diseñó varias reformas que buscaban el desarrollo económico del país (Lofstrom 1996). Una de esas reformas era la modernización del sistema penitenciario, en especial el de Cundinamarca, que era una región con un desarrollo acelerado en el cual las políticas de disolución de resguardos eran más acentuadas (Rojas 2001). El principal propósito de la reforma penitenciaria era educar a los prisioneros durante la reclusión. Por esa razón Mosquera contrató al famoso arquitecto danés Thomas Reed, quien venía trabajando en la construcción de cárceles modernas. Reed desarrolló varios planos arquitectónicos del panóptico en 1849 y finalmente la prisión fue construida en 1874 (Garzón 2010).

\section{La lógica del panóptico}

Hay que recalcar que Thomas Reed estaba influenciado por las ideas del jurista inglés Jeremy Bentham (Harrison 1983). De acuerdo con Bentham, la filosofía política debía estar basada en el principio "the greatest good for the greatest number of people". Según Bentham, ello no sólo se lograba con mejores leyes sino con reformas en los espacios de la prisión. En su opinión, la prisión no debía sólo contener los cuerpos sino colonizar la mente de los individuos. En sus palabras una prisión debía ser:

\begin{abstract}
A building circular... The prisoners in their cells, occupying the circumference -The officers in the centre. By blinds and other contrivances, the Inspectors concealed... from the observation of the prisoners: hence the sentiment of a sort of omnipresence-The whole circuit reviewable with little, or... without any, change of place. One station in the inspection part affording the most perfect view of every cell (Bentham 1798:1).
\end{abstract}

La nueva teoría sobre la prisión esgrimida por Bentham argumentaba que esta debía ser un espacio arquitectónico que beneficiara directamente el proceso educativo que debían adelantar los reos. Después de todo, ser prisionero era el resultado de una falla en el proceso de formación de ciudadanos. De tal suerte, la principal tarea de la prisión, como 
una extensión del Estado, era educar a los prisioneros para hacerlos ciudadanos productivos. En la actualidad el Museo tiene esa misma función (educar), aunque ello no implique la residencia permanente como consecuencia de una acción delictiva. Por ello las reformas hechas en el siglo XIX al sistema penitenciario enfatizaban en la enseñanza de oficios, principalmente manuales (Foucault 1977). En específico, la teoría de Bentham se basaba en la idea de que el Estado vigilara constantemente a sus ciudadanos a través de diversas instituciones como la escuela, la fábrica y la prisión.

Ya que era imposible vigilar cada ciudadano, la escuela debía ser el primer instrumento para producir el "sentiment of omnipresence". Si esa fase fallaba, aun en la fábrica, la prisión debía intervenir produciendo un "sentiment of omnipresence" más realista. Según la teoría de Bentham, no era necesario castigar los cuerpos sino controlar las mentes (Foucault 1977). Según lo anterior, la arquitectura moderna estaría caracterizada por el deseo de control a través de la educación (Haraway 1991). En este sentido la fábrica, la prisión, y la escuela, serían espacios diferenciados de la misma episteme.

En criterio de Bentham, el Estado debía ser el ente encargado de la producción de ciudadanos con las habilidades requeridas en el mercado. Dicha lógica representa lo que el historiador Frank Safford denominó "el ideal de lo práctico" (Safford 1989). Por esa razón, el Estado colombiano en el siglo XIX intentó abolir todas aquellas epistemes que no concebían la producción como prioritaria; de allí la existencia de todas aquellas normas que intentaban abolir lo indígena. Ante esa abolición, era necesario crear instituciones que reciclaran los vestigios de esas otras epistemes ubicándolas en el pasado. Como lo señalaron los Mama que Amado Villafaña filmó, los Sewá siempre estuvieron en prisión, aun antes de ser trasladados al Panóptico (Amado Villafaña, comunicación personal, 2010).

Lo que resulta claro es que los museos nacionales son engranajes del sistema de producción de ciudadanos. Dada esa función, resulta fácil convertir una prisión en un museo. A pesar de que hay una relación entre la historia de la museografía en Colombia y la disolución de resguardos indígenas, dicha relación no es reflexionada en el Museo Nacional. De tal suerte, los vestigios materiales de comunidades diezmadas son naturalizados como "registro arqueológico". No gratuitamente en la década de 1950 cuando se perseguían a los indígenas que defendían sus tierras en el departamento del Cauca, se comenzaron a organizar las primeras colecciones en la universidad de la región, la Universidad del Cauca. En un texto editado en 1952 en dicha institución (Otero 1952), un notable etnólogo local decía que los indígenas de la región de Tierradentro, denominados "paeces", no podían ser los descendientes de esos seres maravillosos que habían construido las bellas tumbas que estudiaban los arqueólogos. A pesar de que los Nasa consideran Tierradentro como un sitio paradigmático de su cultura, contraviniendo la interpretación del famoso etnólogo, actualmente instituciones como el Museo del Oro, en Bogotá, manifiestan directamente que los constructores del sitio nada tienen que ver con los actuales nativos que habitan sus alrededores. Un cartel que habla sobre la orfebrería del suroccidente de Colombia dice:

los españoles lo llamaron Tierradentro porque se sentían encerrados... Desde el año 1000 a.C. (...) vivieron allí sociedades de agricultores y ceramistas... Los actuales indígenas paeces llegaron a la región después de la conquista (Museo del Oro, segundo piso, Región arqueológica Tierradentro, ver Figura 2).

\section{El guión museográfico del Museo Nacional de Colombia}

El Museo Nacional tiene como principal propósito coleccionar, conservar y exhibir los objetos que representan los eventos de la independencia del imperio español, como también los que evocan diversos momentos históricos del país (Segura, 1995).

No existen muchas investigaciones críticas que hablen de la historia del Museo en dos sentidos: como un edificio que representa un momento histórico del sistema de prisiones del país, como una institución cuya tarea primordial es la "preservación de la memoria nacional" (Segura, 1995). Desde hace mucho tiempo el arqueólogo colombiano Cristóbal Gnecco (1999) ha escrito sobre lo problemático de la tarea en vista de que la construcción de la memoria nacional implica la exclusión de las memorias que le precedieron (Serge 2005).

Así que antes de exponer el guion del Museo Nacional, es importante preguntar ¿Cuáles son los criterios que se utiliza para seleccionar ciertos discursos y ciertos objetos? ¿Cuál es el marco temporal y epistémico que abarcan esos criterios? ¿Cómo 


\section{La gente y el oro \\ en el Alto Magdalena}

\section{People and Gold in the Upper Magdalena Region}

El nororiente del departamento del Cauca tiene un paisaje

lo llamaron Tierra adentro porque se sentían encerrados

entre montañas. Desde el año 1000 a.C. y a lo largo de los periodos Temprano, Medio y Tardío, vivieron allí sociedades

de agricultores y ceramistas que labraron cámaras mortuorias, tallaron estatuas de piedra y trabajaron la orfebrería. Los actuales indigenas paeces llegaron a la región después de la conquista.

\section{The landscape in the north eastern part of Cauca province is one of mountain knots}

Figura 2. Cartel sobre Tierradentro en el Museo del Oro, Bogotá (Foto del autor).

Poster about Tierradentro in the Gold Museum, Bogotá (Photo by the author).

esos criterios están relacionados con ejercicios hegemónicos del Estado contra comunidades locales?

Exponer el guion del Museo Nacional desde la perspectiva indígena resulta un ejercicio interesante para responder esas preguntas. En el caso del primer interrogante, es evidente que el criterio que subyace la preservación y exhibición tiene que ver con mantener los valores impuestos por la colonia: cristianismo y monolingüismo (castellano como lengua vernácula), como sistemas simbólicos dominantes (Gnecco y Londoño 2008).

Aunque el Museo Nacional no lo dice abiertamente en un cartel, estos valores se proyectan a lo largo de sus tres pisos. Como es de suponerse, en una institución basada en la modernidad, el primer piso está dedicado a "Los primeros pobladores". Las antiguas celdas del Panóptico en el primer piso han sido llenadas con objetos arqueológicos que abarcan una época tan distante como la frontera entre el Pleistoceno y el Holoceno (10.000 a.p.). En ese mismo piso, en otra sala, hay una serie de exhibiciones sobre "Las Sociedades prehispánicas sedentarias". Otra sala recrea momentos de la conquista con maquetas de barcos españoles armados de cañones que llegan a playas rodeadas de indígenas. En el pasillo que conduce a estas salas, hay una exposición de un cuerpo con algunas ofrendas de oro, lo que parece simular un pequeño "Museo del oro"4.

En la sala de las sociedades sedentarias hay un afiche con algunas fotos del famoso sitio arqueológico "Ciudad Perdida". En ese afiche hay algunas imágenes de los kogis que viven alrededor del sitio. El poster tiene la siguiente sentencia: "Los restos materiales de las culturas desaparecidas todavía son objeto de saqueo y guaquería, actividades que inician con la entrada de la conquista, española". En la parte baja del afiche hay una foto de Amado Villafaña que se encuentra arrodillado con su cámara fotográfica apuntando a un objetivo. A pesar de que Amado Villafaña cuestionó la discontinuidad arqueológica cuando llevó a los Mama al Museo Nacional, el cartel supone que los sitios arqueológicos de la Sierra Nevada de Santa Marta son "Ciudades Perdidas" que los arqueólogos encontraron. La mayor parte de la evidencia sugiere que estos sitios, 
construidos con lajas de piedra con las cuales se hacían plataformas, son sagrados en tanto están fabricados con Sewá (Amado Villafaña, comunicación personal, 2010). Dicho argumento podría explicar, de manera alternativa, la visión de muchos arqueólogos que a inicios del siglo XX (Mason 1931, Mason 1938) concibieron la no residencia permanente en estos lugares como abandono. No se trataría de un abandono, sino de una visita ritual, esporádica, que supone ciertas restricciones en tanto en esos sitios se hacen adivinaciones y consultas.

En términos específicos, hay que resaltar que el primer piso está dedicado a desvincular lo indígena del presente. Se trata de allochronism (alocronismo) expuesto por Johannes Fabian (Fabian 1983). Según este dispositivo retórico, el otro es representado en una dimensión temporal diferente a la de la modernidad generando con ello su conversión en reliquia. Se exalta al indígena del pasado y se condena en presente (Gnecco 1999).

La discontinuidad entre las culturas arqueológicas y las comunidades indígenas contemporáneas ha sido un tema clave en el proceso de conquista de los grupos indígenas. En el trabajo de la antropóloga Mónica Espinosa (2009) se puede ver claramente cómo en la década de 1930 el pleito entre el Estado y algunas comunidades indígenas tenía como base de disputas la continuidad o no de la herencia indígena. En ese estudio aparecen en detalle documentos judiciales que deslegitimaban los reclamos de continuidad de varios grupos indígenas de la región de Tolima, Colombia (Espinosa 2009:177, 184). Lo interesante de dichos reclamos era que estaban a la cabeza del líder indígena Manuel Quintín Lame, de quien el guión del Museo tiene reservada una celda en el tercer piso.

La representación del primer piso termina con algunos objetos de la conquista española. El más conspicuo de esos objetos es un cañón. Este artefacto sugiere que la conquista fue inevitable, y dado que no hay ninguna referencia crítica sobre este evento, sorprende que se excluyan las voces indígenas que cuestionan la celebración del 12 de octubre de 1492 (Mignolo 2005).

Siguiendo la organización estratigráfica del Museo Nacional, el segundo piso alberga una sala denominada "Fundadores de la República". En dicha sala están los objetos que representan la historia del Virreinato de la Nueva Granada. Muchos de esos objetos corresponden a artefactos hechos con plata $\mathrm{y}$ oro, que se usaban para los servicios religiosos.
No sobra decir que la empresa colonial se basó en la sujeción y dominación de las comunidades indígenas, y que con base en dicha sujeción diversas instituciones como la Iglesia o la propia Corona despojaron a muchos nativos de objetos hechos con plata y oro. Un elemento fundamental de dicha dominación era valorar las culturas locales como herejes. De allí que una de las primeras acciones de las fundaciones era extirpar idolatrías, es decir, destruir y apropiarse de objetos de los nativos (Langebaek 2007). Desde el punto de vista indígena, lo que representa esta sala es una valoración positiva de los principios culturales que se usaron para expropiarles riquezas a los indígenas.

Dado que el Museo Nacional implementó unas actualizaciones leves, en el segundo piso hay un pequeño televisor que pasa un filme con imágenes y voces de afrocolombianos. Se trata de una pequeña interpolación que representa las reformas que el Museo adelantó a inicios de la década del 2000. En una parte del filme aparece una mujer explicando el sentido de algunos rituales funerarios (Figura 3 ).

Siguiendo hacia adelante del televisor, hay otra sala que contiene objetos del siglo XIX. Hay muchas pinturas de políticos colombianos, algunas pertenencias de notables de la época, como sillas de montar, cerámica, lapiceros y relojes. Terminando esa sala hay un afiche que se nota fue puesto allí hace poco (otra interpolación), pues desentona con la línea argumentativa de la sala. Ese afiche señala que la historia es una construcción. El cartel sugiere que en esa construcción hay una "monumentalización del pasado" (Segundo piso, Museo Nacional).

Las interpolaciones que se pueden hallar en la exposición permanente, ciertamente encuentran eco en la polémica que existe entre la antigua curadora del Museo, la señora Beatriz González y la actual curadora (2011) Cristina Lleras (Junca 2011a y 2011b). Las diferencias entre estas dos personas no sólo son generacionales, sino conceptuales. Para Beatriz González, quien fuera curadora por casi dos décadas, el Museo Nacional debe tener como misión fundamental "preservar la memoria del país". Para Cristina Lleras, la nueva curadora, se trata de ir más allá de la preservación y producir una experiencia. Para Beatriz González "la misión del Museo no es permanecer lleno de gente, sino preservar la memoria del país" (Junca 2011a). A Cristina Lleras le parece que "al Museo de nada le sirve tener unas colecciones fantásticas si nadie lo visita" (Junca 2011b). 


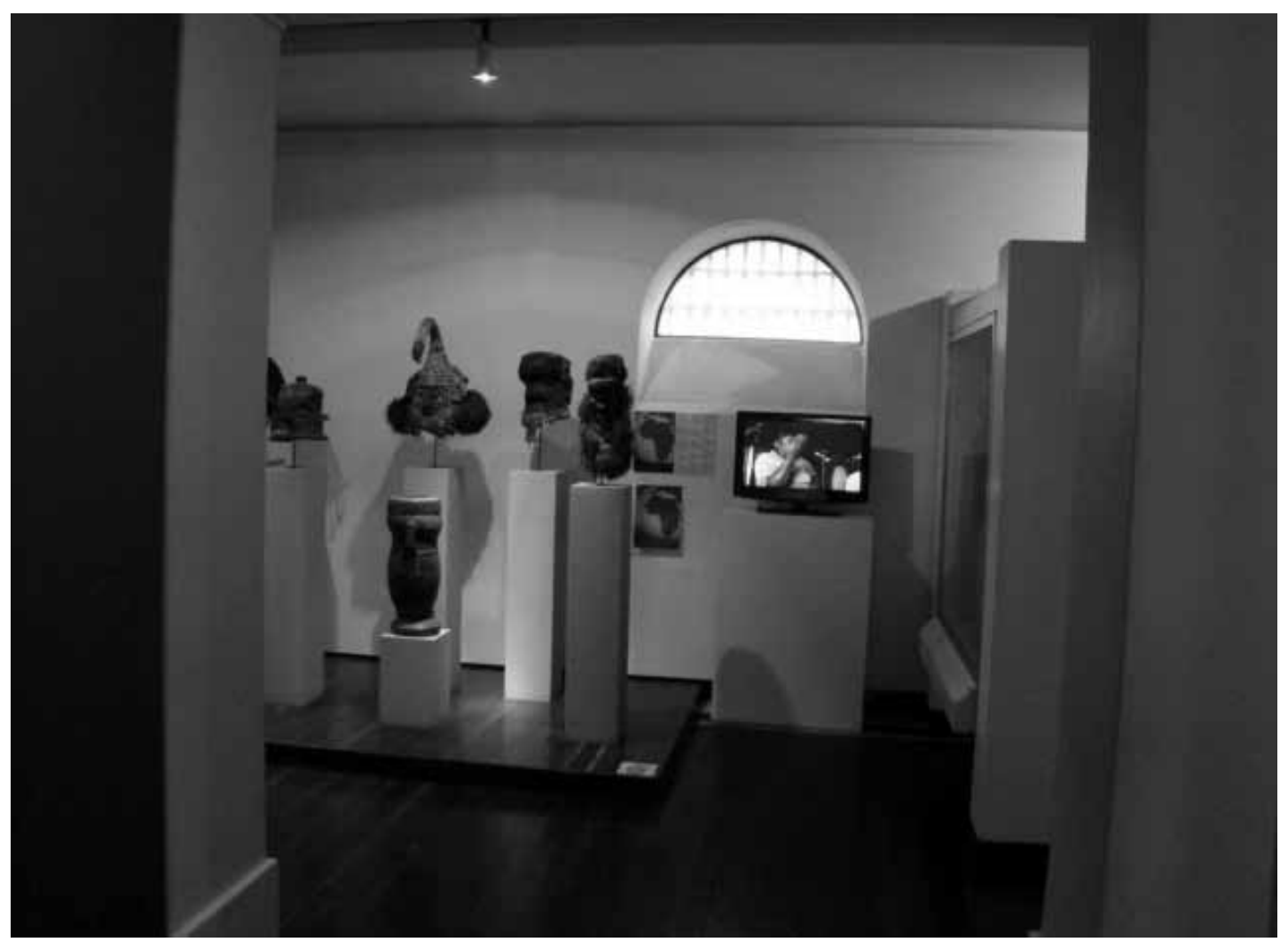

Figura 3. Museo Nacional de Colombia, segundo piso. Televisor con imágenes de afrodescendientes (Foto del autor). National Museum of Colombia, second floor. TV images of afrocolombian people (Photo by the autor).

Evidentemente desde hace algunos años, los visitantes al Museo han encontrado no sólo exposiciones itinerantes internacionales, como esculturas chinas, egipcias e incaicas, sino también representaciones donde hay interacción entre el visitante y el Museo. Como lo sugiere Beatriz González, para fortuna de ella, esas intervenciones no han afectado la estructura narrativa básica (Junca 2011a); no sobra llamar la atención de que esas formas de representación fueron heredadas de la cultura histórica del héroe español (Colmenares 1987). De allí que el Museo Nacional le dé tanta importancia a objetos de próceres como Simón Bolívar o Francisco de Paula Santander. Bajo esa figura retórica, los indígenas son seres anónimos y los criollos personalidades determinadas.

Finalmente, el tercer piso está dedicado al siglo XX. En este piso, las colecciones más importantes son las pinturas de artistas colombianos como Fernando Botero, Enrique Grau Araujo y Luis Alberto Acuña. Además, hay algunas imágenes de Manuel Quintín Lame acompañadas de comentarios sobre su labor en la defensa de los indígenas. También se puede encontrar información sobre la masacre de las Bananeras, ocurrida en el norte de Colombia a inicios del siglo XX (Striffler y Moberg 2003). Igualmente, hay una pequeña sala sobre Carlos Pizarro, líder de izquierda, máximo comandante del M-19, quien fuera asesinado en medio del proceso de paz que el gobierno colombiano adelantaba con esta organización en la década de 1980. Finalmente, se puede encontrar, al final de la exposición, una sala con objetos contemporáneos como lavadoras, televisores y un pequeño cinema.

Inexplicablemente la exhibición del Museo termina en la década de 1960. Esto desconecta ciertos fenómenos históricos con situaciones contemporáneas. Por ejemplo, la multinacional Chiquita Brand, productora de banano, recientemente fue encontrada culpable de apoyar grupos paramilitares los cuales desplazaron a muchas comunidades locales de sus lugares de vivienda. En el periodo paramilitar, inclusive, muchos líderes indígenas fueron asesinados, en especial líderes kankuamos, 
un grupo de la vertiente oriental de la Sierra Nevada de Santa Marta (Morales 2011).

La violencia en Colombia aún no termina y lamentablemente instituciones como el Museo Nacional intentan evitar comentar esta situación con la excusa de que allí se exhiben los valores representativos de la nacionalidad, o de que allí se producen simulacros históricos. Como lo han sugerido algunos investigadores (Rojas 2001, Serge 2005), es precisamente la construcción de la identidad nacional lo que produce violencia, pues es necesario normalizar la población (Gnecco y Londoño 2008). Seguramente, volver las antiguas prisiones en museos no es una estrategia que ayude a resolver los problemas que genera la política de la construcción de la identidad nacional. Tampoco ayuda que en esa representación, todo el componente étnico sea mostrado como una reliquia arqueológica, o que la franja afrocolombiana sea mostrada mediante una pequeña pantalla de televisor donde circula un video que parece un comercial de televisión.

Para trascender ese marco de representación, hegemónico, valdría la pena acoger la propuesta de los indígenas de la Sierra Nevada de Santa Marta: abrir la prisión y dejar que los espíritus recobren la libertad, mostrar la época del Virreinato de la Nueva Granada como una de explotación y expropiación, enseñar la república como el periodo de la instauración de una violencia física y epistémica sistemática contra comunidades locales. Tal vez así se pudiera tomar partido en lo que Walter Mignolo ha llamado la "herida colonial" (Mignolo 2005). Acoger esa propuesta significaría que Colombia anduviera los pasos de la repatriación, tal como ha ocurrido en otros lugares del mundo (Endere 2002; Zimmerman 1996). Tal vez así pudiera encontrarse una vía más democrática de representar las naciones en un mundo posnacional (Appadurai 1996).

Agradecimientos: Este texto no se hubiera podido escribir sin el estímulo académico de Amado Villafaña. Igualmente muchas de las ideas exploradas tuvieron lugar por la influencia de Alejandro Haber y Cristóbal Gnecco (sin ser ellos responsables de las mismas). Asimismo, debo la oportunidad de discutir una versión muy preliminar de esta investigación, en la Universidad de Indianapolis, a Larry Zimmerman, Julie Hollowell, Joan Gero y Claire Smith; todo ello dentro del marco del congreso "Indigenous Peoples and Museums: Unraveling the Tensions" que se celebró en esa universidad en el verano del 2011. Aprovecho este espacio para agradecer los comentarios de los evaluadores anónimos, los cuales permitieron precisar elementos en el texto; igualmente, quisiera extender mis agradecimientos a Carlos Coronado y Tatiana Sánchez, de la Universidad del Magdalena, quienes colaboraron con la revisión de las traducciones incluidas en el texto. Finalmente agradezco a los espíritus que me han protegido en estos años de residencia en Santa Marta.

\section{Referencias Citadas}

Appadurai, A. 1996. Modernity at Large. Cultural Dimensions of Globalization. University of Minnesota Press, Minneapolis.

Bentham, J. 1798. The Panopticom. (s.f.). http://www.utilitarianism.com/panopticon.html (11 septiembre 2011).

Bonilla, V. 2006 [1968]. Siervos de Dios y Amos de Indios. El Estado y la Misión Capuchina en el Putumayo. Editorial Universidad del Cauca, Popayán.

Bushnell, D. 1966. El Régimen de Santander en la Gran Colombia. Universidad Nacional-Tercer Mundo, Bogotá.

Canal RCN. 2012. Parque Tayrona ya no es del Estado. (10 enero 2012). http://www.canalrcnmsn.com/noticias/ parque_tayrona_ya_no_es_del_estado_le_quitaron_12000_ hect\%C3\%A1reas_naci\%C3\%B3n (15 enero 2012).

Colmenares, G. 1987. Las Convenciones Contra la Cultura. Tercer Mundo, Bogotá.

Castro-Gómez, S. 2000. Ciencias sociales, violencia epistémica y el problema de la "invención del otro". En La Colonialidad del Saber: Eurocentrismo y Ciencias Sociales, editado por E.
Lander, pp. 141-165. Clacso-Unesco, Perspectivas latinoamericanas, Buenos Aires.

Centro de Comunicaciones Zhigoneshi s.f. Kemakumake. Director Amado Villafaña. Santa Marta, Colombia.

- - - s.f. Sewá. Director Amado Villafaña. Colombia, Santa Marta. - - - 2009. Palabras Mayores. Director Amado Villafaña. 48 minutos. Santa Marta, Colombia.

Correa, P. y D. Torres 2011. Los verdaderos dueños del Tayrona. El Espectador. (29 octubre del 2011). http://www.elespectador. com/impreso/cultura/vivir/articulo-308305-los-verdaderosduenos-del-tayrona (12 enero 2012).

Endere, M. 2002. The reburial issue in Argentina: a growing conflict. En The Dead and their Possessions: Repatriation in principle, Policy and Practice, editado por C. Forde, J. Hubert y P. Turnbull, pp. 266-83. Routledge, Londres.

Espinosa, M. 2009. La civilización Montés. La Visión India y el Trasegar de Manuel Quintín Lame en Colombia. Universidad de los Andes, Bogotá. 
Fabian, J. 1983. Time and the Other. How Anthropology Makes its Object. Columbia University Press, New York.

Foucault, M. 1966. Les Mots et les Choses (Une archéologie des sciences humaines). Gallimard, Paris.

- - - 1977. Discipline and Punish. The Birth of the Prison. Penguin, Harmondsworth.

Friede, J. 1963. Problemas Sociales de los Arhuacos: Tierras, Gobiernos, Misiones. Universidad Nacional, Bogotá.

Gaitán, F. 2006. Golden alienation. The uneasy fortune of the Gold Museum in Bogotá. Journal of social archaeology, 6(2): 227-254

Garrido, M. 1993. Reclamos y Representaciones. Variaciones sobre la Política en el Nuevo Reino de Granada, 1770-1815. Banco de la República, Bogotá.

Garzón, M. 2010. En busca de la prisión moderna: la construcción del panóptico de Bogotá, 1848-1878. Cuadernos de Curaduría. Museo Nacional, Bogotá.

Gnecco, C. 1999. Sobre el discurso arqueológico en Colombia. Boletín de Antropología, 30:147-165. Medellín.

Gnecco, C. y W. Londoño 2008. Representaciones de la alteridad indígena en el discurso jurídico colombiano Colombia. En Representaciones Jurídicas de la Alteridad Indígena, editado por C. Gnecco y H. Gómez, pp. 25-94. Colciencias, Bogotá.

Gnecco, C. y C. Hernández 2008. History and its discontents. Stones statues, natives histories, and archaeologists. Current Anthropology 49:439-466.

González, L. 2010. Ciudad y Arquitectura Urbana en Colombia, 1980-2010. Universidad de Antioquia, Medellín.

Haber, A. 1999. Uywaña, the house and it indoor landscape: Oblique approaches to, and beyond, domestication. En The Prehistory of Food: Appetites for Change, editado por C. Gosden y J. Hather, pp. 59-82. Routledge, Londres.

- - - 2008. ¿A dónde están los 99 tíficos? Notas de campo de arqueología subjuntiva. En Sed non satiata II. Acercamientos Sociales en la Arqueología Latinoamericana, editado por F. Acuto y A. Zarankín, UNCa, Catamarca.

- - - 2009. Animism, relatedness, life: Post-Western perspectives. Cambridge Archaeological Journal 19:418-30.

Haber, A. y M. Gastaldi 2006. Vida con palas. Antípoda. Revista de Antropología y Arqueología 2:275-302.

Haraway, D. 1991. Simians, Cyborgs and Women: The Reinvention of Nature. Routledge, New York.

Harrison, R. 1983. Bentham. Routledge y Kegan Paul, Londres. Junca, H. 2011a. Entrevista a Beatriz González. Arcadia 68:12-13. - - - 2011b. Entrevista a Cristina Lleras. Arcadia 68:14-15. Bogotá. Kusch, R. 1975. América Profunda. Bonum, Buenos Aires.

Langebaek, C. 2003. Arqueología Colombiana. Ciencia, Pasado y Exclusión. Colciencias, Bogotá.

- - - 2007. La idolatría de los indios en el siglo XVII: El caso de los Arhuacos en 1628. En Indios y Españoles en la Antigua Provincia de Santa Marta, Colombia. Documentos de los Siglos XVI y XVIII, editado por C. Langebaek, pp. 221-248. Universidad de los Andes, Bogotá.
Liss, P. 1983. Atlantic Empires: The Network of Trade and Revolution, 1713-1826, Johns Hopkins University Press, Baltimore.

Lofstrom, W. 1996. La Vida Íntima de Tomás Cipriano de Mosquera (1798-1878). El Áncora, Bogotá.

Londoño, W. 2003. La "reducción de salvajes" y el mantenimiento de la tradición. Boletín de Antropología 34:235-251. Medellín.

Looper, M. 1996. The iconography and social context of tairona gold pectorals. Journal of Latin American Lore 19:101-128.

Mason, A. 1931. Archaeology of Santa Marta, Colombia. The Tairona culture. Pt. I: Report on field work. Field Museum of Natural History, Chicago.

Mason, G. 1938. Culture of the Taironas. Doctoral dissertation. Department of Anthropology University of Southern California, Los Angeles.

Mignolo, W. 2000. Local Histories / Global Designs. Coloniality, Subaltern Knowledges and Border Thinking. Princenton University Press, Princenton.

- - - 2005. La Idea de América Latina. La Herida Colonial y la Opción decolonial. Gedisa, Barcelona.

Morales, P. 2011. Los idiomas de la reetnización. Corpus Christi y pagamentos entre los indígenas kankuamo de la Sierra Nevada de Santa Marta. Universidad Nacional, Bogotá.

Otero, J. 1952. Etnología Caucana. Editorial Universidad del Cauca, Popayán.

Pineda, R. 2004. Escuela de antropología colombiana. Maguaré 18:59-85.

Preuss, K.T. 1919. Forschungsreise zu den Kágaba-Indianem der Sierra Nevada de Santa Marta in Kolumbien. Anthropos $14: 314-404$

Reichel-Dolmatoff, G. 1985. Los Kogi. Una tribu de la Sierra Nevada de Santa Marta, Colombia. II tomos. Procultura, Bogotá.

Ríos, G. 2004. López, Pedro. Biografía. Biblioteca virtual del Banco de la República. (6 junio 2004) http://www.banrepcultural. org/blaavirtual/biografias/lopepedr.htm (10 de septiembre 2011).

Rojas, C. 2001. Civilización y Violencia: la Búsqueda de la Identidad en la Colombia del Siglo XIX. Norma, Bogotá.

Safford, F. 1989. El Ideal de lo Práctico. El Desafío de Formar una Élite Técnica y Empresarial en Colombia. Universidad Nacional-El Ancora, Bogotá.

- - - 1991. Race, integration and progress: Elite attitudes and the Indian in Colombia, 1750-1870. Hispanic American Historical Review 71:7-21.

Samper, D. 2011. ¿Indígenas en el Tayrona? ¿Cuáles indígenas? El Tiempo (15 octubre 2011). http://www.eltiempo.com/politica/ ARTICULO-WEB-NEW_NOTA_INTERIOR-10595410.html (12 enero 2012).

Sánchez, E. 2003. El Museo del Oro. Boletín Cultural y Bibliográfico 40(64):2-48.

Segura, M. 1995. Itinerario del Museo Nacional de Colombia 1823-1994. Museo Nacional de Colombia, Bogotá.

Serge, M. 2005. El revés de la Nación. Territorios salvajes, fronteras y tierras de nadie. Universidad de los Andes, Bogotá 
Striffler, S. y M. Moberg 2003. Banana War. Power, Production and History in the Americas. Duke University Press. Durham and London.

Tate, W. 2007. Counting the dead. The culture and politics of human rights activism in Colombia. University of California Press, Berkeley.

van Kessel, J. y D. Condori 1992. Criar la Vida. Trabajo y Tecnología en el Mundo Andino. Vivarium, Santiago.
Villafaña, D. 2005. Ordenamiento territorial ancestral (1 febrero 2005) http://www.uninorte.edu.co/extensiones/IDS/ponencias/ PONENCIAS $\% 20$ AGOSTO $\% 2011$ /ordenamiento\%20territorial\%20indigena.pdf (15 diciembre 2011).

Walker, G. 1979. Política Española y Comercio Colonial, 1700, 1789. Ariel, Barcelona.

Zimmerman, L. 2006. Liberating archaeology, liberation archaeologies, and WAC. Archaeologies 2:85-95.

\section{Notas}

1 Es importante aclarar que acá se usa la terminología nativa en la versión de Danilo Villafaña. Hay que anotar que las traducciones de estos conceptos son escasas, y que sólo disponemos de pocas versiones locales como la de Villafaña.

2 Se debe señalar que los reclamos por objetos indígenas que se encuentran en este tipo de colecciones, para el caso de Santa Marta, apenas comienza a tener una dinámica visible. En todo caso, queda abierta la pregunta de si estos pequeños eventos de petición de devoluciones no son también síntomas de cambio de las habituales formas en que se han dado las relaciones entre las comunidades indígenas y las instituciones estatales como la universidad. Estos cambios, evidentemente, deberían ser ponderados en una investigación particular, interés que desborda la reflexión planteada en este texto.

3 Agradezco a Cristóbal Gnecco por la recomendación de esta referencia.

4 Para visión crítica del Museo del Oro véase Gaitán (2006). 
